\title{
Building a Sustainable Economy: Opportunities and Prospects
}

\author{
Yulia Evdokimova ${ }^{1, *}$, Elena Egorova $^{2}$, Olga Shinkareva ${ }^{3}$ \\ ${ }^{1}$ State educational institution of higher professional education "Moscow City Government University of \\ Management", Moscow, Russia \\ ${ }^{2}$ Russian State Social University, Moscow, Russia \\ ${ }^{3}$ Moscow City University, Moscow, Russia \\ ${ }^{*}$ Corresponding author. Email: uaevdokimova@mail.ru
}

\begin{abstract}
This issue studies the sectoral specifics of a sustainable economy, analyses the necessary measures aimed at the formation of a sustainable economy with an economic, environmental and social focus. The main directions for the analysis of the positions of a sustainable economy were identified: objective analysis of public benefits, climate economics, analysis of the possibilities of green investment, integrated sustainability. The directions of stimulation of sustainable development of economy and their probable efficiency are considered. Positions of interaction between the state, the financial sector and the business sector were studied and summarized in order to achieve a positive effect on the formation and development of a sustainable economy.
\end{abstract}

Keywords: Sustainable economy, Investment, Economic effect, Green finance, Clean energy, Energy efficiency.

\section{INTRODUCTION}

A sustainable economy is an economy capable of providing a good quality of life for society [1].

Economic sustainability is based on the well-being of society. Well-being can be considered from three dimensions:

- Economics. This component includes income, economic stability and employment.

- Investments. This includes education, health and infrastructure, created through policies and programmes that ensure the well-being and development of society.

- Stability. It highlights the environment and three factors that have a positive impact on the possibilities of social integration: equality, strong civil society and objective good governance [2].

Sustainable development - development that meets the needs of society of the current time period. However, meeting such needs should not threaten future generations and their capabilities [3].

Sustainable development is directed to universal improvement of welfare and protection of the planet taking into account a complete solution of questions of elimination of poverty, increase in economic growth, problems of education, health care, social protection and employment, climate change and protection of ecology and the environment [4].

The emergence of the concept of sustainable development in international practice is associated with the identification of growing environmental problems that threaten the sustained economic development of society and require comprehensive innovative solutions at the national and supranational levels.

A sustainable economy envisages the development of public infrastructure, needs significant investment in order to meet the steadily growing needs of society. But investment alone is clearly not sufficient to ensure the sustainable development of States. An integrated approach is needed to consider all existing directions of progress towards sustainable development, to explore the possibilities and significance of each of these directions, as well as to assess the economic impact of the introduction of new forms and tools that contribute to the development of a sustainable economy and improve the quality of life of all segments of society. 


\section{MATERIALS AND METHODS}

This study is based on the research of the World Economic Forum and the Russia's National Economic Development Institution VEB.RF, the materials of the World Wildlife Fund, the United Nations, the Bank of Russia.

The main methods used in the process of conducting this study are analysis and synthesis, generalization, comparison. These methods make it possible to most harmoniously, fully and effectively reveal the opportunities and prospects for the formation of a sustainable economy.

\section{RESULTS AND DISCUSSION}

A sustainable economy will be treated differently depending on the industry. In agriculture, a sustainable economy is associated with the eradication of poverty in small-scale farmers' communities, with productivity growth on a level with population growth, and the obligatory restoration of the environment. For the automotive industry, a sustainable economy is more likely to be associated with the widespread introduction of self-contained clean energy vehicles, with the fullformat implementation of a high-vehicle-intensive sharing model. In the finance sector, investors will be bound to take full account of environmental, social and managerial aspects in their approach to investment [5].

The analysis of the position of a sustainable economy and the follow-up to its formation can be presented in several areas:

1. Objective analysis of public benefits. When making decisions within the framework of the possibilities of implementing any market projects, you need to own information in order to understand how these decisions will affect the public interest. Often, such information is partial, resulting in the need to identify the true costs and benefits of these solutions to society. The difficulty of assessing this kind arises from the complexity of quantitative analysis in standard economic analysis methods, which can be distorted.

2. Climate economics. The economic costs of climate change are expected to be enormous. Costs of climate change depending on the current pollution scenario. The costs of climate change need to be assessed from both market and non-market dimensions of economic wellbeing. Cost-effective options should be envisaged and calculated.

3. Analysis of green investment opportunities. Investments in environmentally sound infrastructure solutions are more likely to provide more cost-effective ways of achieving the environmental quality results of businesses or countries than conventional investments in other standard infrastructure. There is a need to quantify the costs and benefits of restoring water bodies, forests, rivers and coastal ecosystems as an alternative to expensive technological solutions for their infrastructure needs.

4. Integrated sustainability. This concept combines the positions of environmental, economic and social sustainability. It is necessary to comprehensively and as accurately as possible determine and measure sustainability using the most modern indicators and methods. It is imperative to identify, stimulate and scale initiatives that contribute to sustainability. In addition, there is a need for constant control on the opposite side, providing an opportunity to suppress initiatives that destroy natural, human, built and social capital over time.

The binding nature of international cooperation and major changes in many sectors can increase the effectiveness of State-positioned measures to promote sustainable economic development. The World Economic Forum includes the following areas:

1. The sustainable future of the labor market. The core of the formation of a sustainable economy should be a long-term and short-term increase in the number and diversity of jobs. For example, after 2008, thousands of new jobs arose in the global economy, as states introduced wind, solar and network projects.

2. Sustainable investment in innovation. The possibilities of business competitiveness growth today are largely connected with the development of innovative technologies and projects. Future leadership can be achieved through investments in technologies such as electric transport and artificial intelligence, sustainable agriculture and clean environment, environmental food, etc. It is equally important to invest in developing countries with insufficient capital, they act as growing markets, important for the near future from the point of view of achieving the goals of sustainable green development. Stimulating private capital with long-term guidance from the State allows for some freedom in the implementation of declared sustainable development projects and confidence in their success.

3. Consumer incentives. A higher consumer interest in environmentally friendly products should be based on its promotion. Transparency of information on environmentally friendly products is essential, but not sufficient. The effectiveness of additional consumer stimulation provides a more effective outcome. An example is the Money for Autostuff program, which encourages the purchase of cleaner cars, improves the climate and reduces air pollution.

4. Creating opportunities and conditions for the use of environmentally friendly energy. The need to move to low-carbon and zero-carbon energy sources to reduce the impact of global warming needs to be accelerated. The introduction of carbon charges could stimulate investment in green infrastructure, pre-empt long-term 
opportunities for investors and enterprises and create a sustainable business interest. Thus, it is possible to achieve rapid stimulation of economic processes and provide the necessary innovations to minimize the damage to the environment today.

5. Modernization of functioning infrastructure. The rapid development of technologies and the limited budget for adapting them to changing conditions create a rapid obsolescence of existing enterprise infrastructure. The lack of modern technologies limits the ability to maintain safe, efficient, flexible activities in emergency and everyday conditions. Infrastructure modernization should be carried out according to new standards that take into account the positions of energy efficiency, air quality and water. It is equally important to minimize long-term operating costs. It is necessary to take into account the stability, uninterrupted equipment and its ability to adapt to modern environmental requirements and conditions.

6. Optimization of state regulation. The complexity and bureaucracy of government regulation of investments in clean projects exist in many countries throughout the energy sector, which discourages potential investors and prevents the full implementation of many projects in this direction [6].

In the context of the coronavirus pandemic, the need for cooperation in the field of digitalization of the economy and sustainable development comes to the fore. Digitalization of all sectors of the economy is based on the interaction of public administration, information technology and entrepreneurial activity. These components can ensure sustainable development and increase the capacity to develop a sustainable economy to meet the needs of society [7].

\section{CONCLUSION}

The realization of sustainable development positions envisages revolutionary changes, from the introduction of new production and consumption models to a serious transformation in the structure of supply and demand, the emergence of new niches, competition will increase [8].

The state, the financial sector and the business sector are driving forces in the economy. In turn, the development of the economy is dictated by the specifics of the development of society and the quality of the environment. Society and the environment are suppliers of resources that are used for the development of the economy. The resource base is transformed into goods and services, private capital, waste and emissions. Economic development, stability and sustainability are not possible if the resources needed to sustain and grow the economy are depleted, adversely affected and not regulated to prevent such an effect. Sustainable economic development is impossible without the responsible activities of all economic actors. The role of the State is to create an effective environment for economic activity.
The financial sector specializes in the redistribution of cash flows into necessary activities that ensure the sustainable development of the economy. The business sector implements sustainable development through their implementation and promotion. Such interaction of parties will provide an opportunity to achieve the envisaged social and environmental results, as well as to ensure the required profitability $[9,10]$.

\section{REFERENCES}

[1] Sustainable economies. Official site of World Wildlife Fund. https://www.wwf.eu/what_we_do/sustainable_econ omies/.

[2] Sustainable Economic Development Assessment and Citizen Well-Being. Official site of Boston Consulting Group.

https://www.bcg.com/industries/publicsector/sustainable-economic-developmentassessment.

[3] Financing for sustainable development. Official site of Bank of Russia. https://cbr.ru/Content/Document/File/123919/press _02072021.pdf.

[4] Sustainable Development Goals. Official site of the United

Nations.

https://www.un.org/sustainabledevelopment/ru/sust ainable-development-goals/.

[5] Transforming Business for a Sustainable Economy. Official site of Bain \& Company, Inc. https://www.bain.com/ru/insights/transformingbusiness-for-a-sustainable-economy/.

[6] 8 steps towards a sustainable economic recovery. Official site of World Economic Forum. https://www.weforum.org/agenda/2020/06/8-stepstowards-a-sustainable-economic-recovery/.

[7] Y. Evdokimova, E. Egorova, O. Shinkareva, Information technology in financial sector Russian Federation - driver of the formation of the Russian economy, E3S Web of Conferences, 208 (2020) pp. 03017.

DOI: https://doi.org/10.1051/e3sconf/202020803017.

[8] Global Trend for Sustainability: Business Opportunities. Department of Multicultural Economic Cooperation, Ministry of Economic Development of Russia. https://www.economy.gov.ru/material/file/45e459d ca8acad4ecdd396aef4448e10/38526748.pdf

[9] Sustainable development and infrastructure. Overview of trends in Russia and the world. Official site of VEB.RF. https://xn--90ab5f.xn-- 
p1ai/downloads/spief_sd_short_final_02.05.2021_

1.pdf.

[10] E. N. Egorova, T. A. Slepneva, V. V. Tretiakova, Modern Ways to Achieve Sustainable Company Growth, Lecture Notes in Networks and Systemsthis link is disabled, 160 LNNS (2021) pp. 116-122. 